\title{
(- Iridoid Sex Pheromone Biosynthesis in Aphids Mimics Iridoid-Producing Plants
}

\author{
Suzanne J. Partridge, ${ }^{[a, b]}$ David M. Withall, ${ }^{[a]}$ John C. Caulfield, ${ }^{[a]}$ John A. Pickett, ${ }^{[c]}$ \\ Robert A. Stockman, ${ }^{[b]}$ Neil J. Oldham, ${ }^{[b]}$ and Michael A. Birkett* ${ }^{[a]}$
}

\begin{abstract}
Biosynthesis of $(1 R, 4 \mathrm{a} S, 7 S, 7 \mathrm{a} R)$-nepetalactol (1) and $(4 a S, 7 S, 7 a R)$-nepetalactone (2) in plants involves iridoid synthase (ISY), an atypical reductive cyclase that catalyses the reduction of 8-oxogeranial into the reactive enol of $(S)$ 8-oxocitronellal, and cyclization of this enol intermediate, either non-enzymatically or by a nepetalactol-related short chain dehydrogenase enzyme (NEPS) that yields the nepetalactols. In this study, we investigated the biosynthesis in vivo of $\mathbf{1}$ and $\mathbf{2}$ in the pea aphid, Acyrthosiphon pisum, using a library of isotopically-labelled monoterpenoids as molecular probes. Topical application of deuterium-labelled probes synthesized from geraniol and nerol resulted in production of ${ }^{2} \mathrm{H}_{4}$-lactol 1 and ${ }^{2} \mathrm{H}_{4}$-lactone 2 . However, deuterium incorporation was not evident using labelled probes synthesized from (S)-citronellol. These results suggest that iridoid biosynthesis in animals, specifically aphids, may follow a broadly similar route to that characterised for plants.
\end{abstract}

Aphids (Homoptera: Aphididae) are major pests of arable and horticultural crops throughout the world, causing damage both directly and indirectly through their feeding behaviour and plant virus transmission. ${ }^{[1]}$ Pheromones and other semiochemicals (naturally-occurring behaviour- or development-modifying chemical signals) play a critical role in the life-cycle of aphids. ${ }^{[2]}$ The female-produced sex pheromone for many pest aphid species mainly comprises the iridoid bicyclic monoterpenoids $(1 R, 4 \mathrm{aS}, 7 \mathrm{~S}, 7 \mathrm{a} R)$-nepetalactol (1) and (4aS,7S,7aR)-nepetalactone (2), but other diastereoisomers of the nepetalactol 1, i.e. $(1 S, 4 \mathrm{a} R, 7 S, 7 \mathrm{a} S)$-nepetalactol (3) and $(1 R, 4 \mathrm{a} R, 7 \mathrm{~S}, 7 \mathrm{aS})$-nepetalactol (4) are also utilized as sex pheromone components by the damson-hop aphid, Phorodon humuli (Figure 1, upper panel). ${ }^{[3]}$ Practical development of the aphid sex pheromone for pest

[a] Dr. S. J. Partridge, Dr. D. M. Withall, Dr. J. C. Caulfield, Dr. M. A. Birkett Biointeractions and Crop Protection Department

Rothamsted Research, Harpenden, Hertfordshire, AL5 2JQ (UK) E-mail: mike.birkett@rothamsted.ac.uk

[b] Dr. S. J. Partridge, Prof. R. A. Stockman, Prof. N. J. Oldham School of Chemistry, University of Nottingham University Park, Nottingham, NG7 2RD (UK)

[c] Prof. J. A. Pickett School of Chemistry, Cardiff University, Cardiff CF10 3AT (UK)

$\square$ Supporting information for this article is available on the WWW under https://doi.org/10.1002/chem.202001356
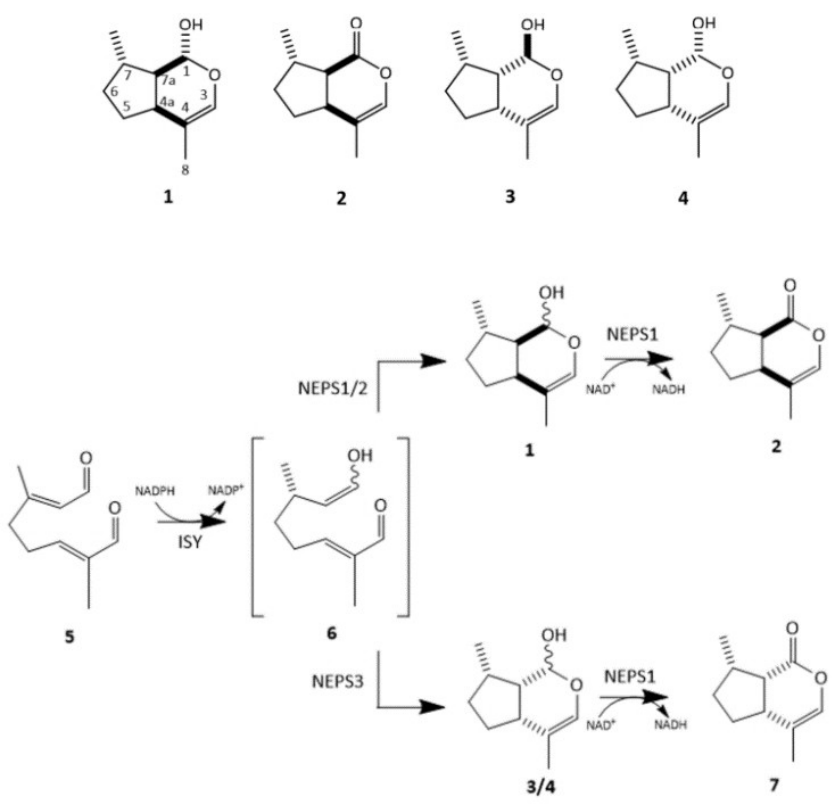

Figure 1. Upper: Aphid sex pheromone components $(1 R, 4 \mathrm{a} S, 7 S, 7 \mathrm{a} R)$-nepetalactol (1), (4aS,7S,7aR)-nepetalactone (2), (1S,4aR,7S,7aS)-nepetalactol (3) and $(1 R, 4 \mathrm{a} R, 7 S, 7 \mathrm{a} S)$-nepetalactol (4). Lower: Iridoid biosynthetic pathway in Nepeta spp plants (modified from Lichman et al., 2019).

management has met with success in the trapping of male aphids during the mating season but has mainly focused on the recruitment of beneficial natural enemy wasps which utilize 2 as a cue for the location of aphid hosts. ${ }^{[4-6]}$ Biosynthesis of 1 and 2 in plants has received much attention, ${ }^{[7-14]}$ with elegant mechanistic studies showing that iridoid synthase (ISY), an atypical reductive cyclase identified from Nepeta spp, Catharanthus roseus, Olea europaea and Antirrhinum majus, catalyses the reduction of 8-oxogeranial into the reactive enol of (S)-8oxocitronellal. ${ }^{[14]}$ Cyclization of this enol intermediate, either non-enzymatically or by a nepetalactol-related short chain dehydrogenase enzyme (NEPS) yields the nepetalactols, which can undergo a final oxidation to nepetalactones (Figure 1 lower). ${ }^{[14]}$ Concurrent to these studies, we have investigated the biosynthesis in vivo of $\mathbf{1}$ and $\mathbf{2}$ in aphids, using the pea aphid, Acyrthosiphon pisum, as the model species, and a library of isotopically-labelled monoterpenoids as molecular probes, to test the hypothesis that biosynthesis of $\mathbf{1}$ and $\mathbf{2}$ in animals, specifically aphids, follows a similar route to that determined in plants. 
<smiles>CC(C)=CCC(C)CC(C)O</smiles>

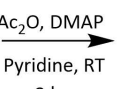

$2 \mathrm{hr}$<smiles>[X]CCC=C(C)C</smiles>

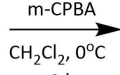<smiles>[X]CCC1OC1(C)C</smiles>

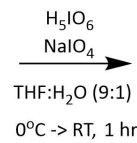

$$
\mathrm{O}_{11}^{\mathrm{X}}{ }^{\mathrm{O}} \mathrm{Y}^{\circ}
$$

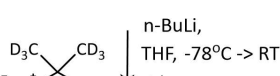
$\mathrm{BrPh}_{3} \mathrm{P}_{(12)}^{+} \overbrace{4 \mathrm{hr}}$
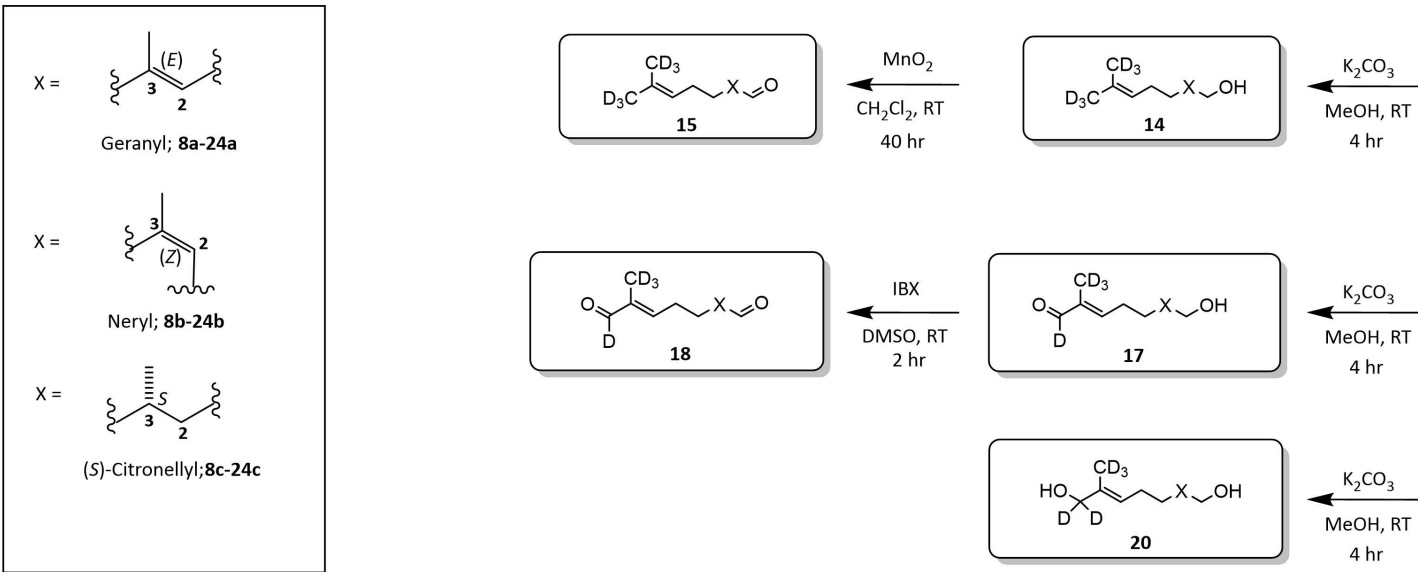

$$
\mathrm{D}_{3} \mathrm{C} \overbrace{13}^{\mathrm{CD}_{3}} \times \mathrm{Y}_{Y}
$$

\begin{tabular}{r|l}
$\mathrm{SeO}_{2}$ & Salicylic acid \\
$\mathrm{t}-\mathrm{BuOOH}$ & $\mathrm{CH}_{2} \mathrm{Cl}_{2}, \mathrm{RT}$
\end{tabular}
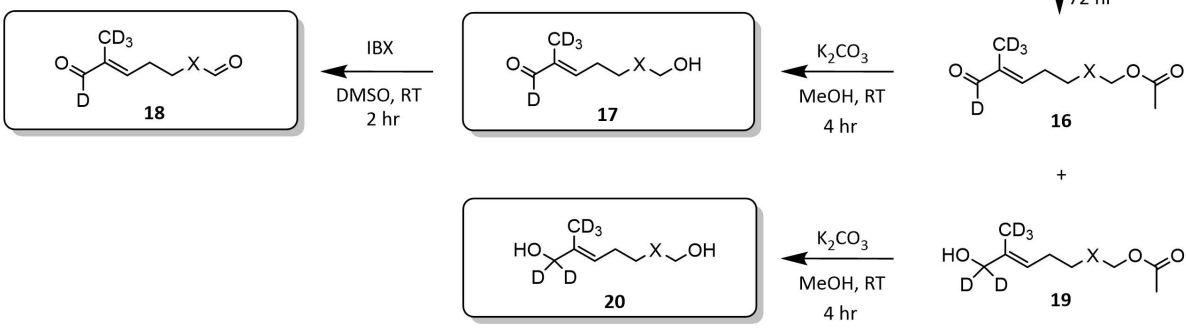

$$
\underbrace{O}_{\text {PPTS } \downarrow} \underset{\mathrm{Chr}}{\mathrm{CH}_{2} \mathrm{Cl}_{2}, \mathrm{RT}}
$$

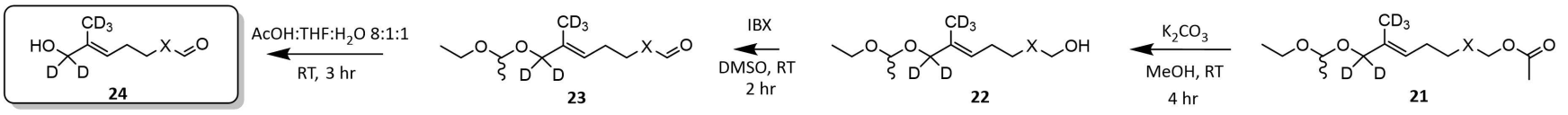

Scheme 1. Production of deuterium-labelled putative sex pheromone precursors and intermediates. Boxed compounds indicate deployment in aphid sex pheromone collections from female pea aphids, Acyrthosiphon pisum.

Synthesis of isotopically-labelled putative precursors was undertaken via multi-step synthesis starting from unlabelled geraniol, nerol and (S)-citronellol (Scheme 1) with the aim of incorporating labelling at the $C_{3}$ and $C_{8}$ positions of the nepetalactone skeleton. ${ }^{[15,16,17]}$ Elaboration of $\left[{ }^{2} \mathrm{H}_{6}\right]$-labelled acetates furnished $\left[{ }^{2} \mathrm{H}_{6}\right]$-alcohols, $\left[{ }^{2} \mathrm{H}_{6}\right]$-aldehydes, $\left[{ }^{2} \mathrm{H}_{5}\right]$-8-hydroxyalcohols, $\left[{ }^{2} \mathrm{H}_{5}\right]-8$-hydroxyaldehydes, $\left[{ }^{2} \mathrm{H}_{4}\right]$-8-oxoalcohols and $\left[{ }^{2} \mathrm{H}_{4}\right]-$ oxoaldehydes. Employing standard topical application methodology of the labelled probes onto the upper (dorsal) surface of female pheromone-producing $A$. pisum at two doses $(0.1 \mathrm{mg}$ and $1 \mathrm{mg}$, Supporting Information) was followed by pheromone collection from aphids using dynamic headspace collection. ${ }^{[18]}$ Coupled gas chromatography - mass spectrometry (GC-MS, $70 \mathrm{eV} \mathrm{EI+)}$ analysis of pheromone collections was undertaken to provide evidence of deuterium incorporation at the $C_{3}$ and $\mathrm{C}_{8}$ positions in the final nepetalactone products (molecular ion $\mathrm{m} / \mathrm{z} 172$ for $\left[{ }^{2} \mathrm{H}_{4}\right]$-nepetalactol $1, \mathrm{~m} / \mathrm{z} 170$ for $\left[{ }^{2} \mathrm{H}_{4}\right]$-nepetalactone 2) (Figure 2).

Coupled GC-MS analysis of pheromone collections following application of $\left[{ }^{2} \mathrm{H}_{6}\right]$-alcohols (14) and $\left[{ }^{2} \mathrm{H}_{6}\right]$-aldehydes (15) showed no evidence of deuterium incorporation (Table 1, see Supporting Information). Application of $\left[{ }^{2} \mathrm{H}_{5}\right]-8$-hydroxygeraniol and $\left[{ }^{2} \mathrm{H}_{5}\right]-8$-hydroxynerol led to the production of $\left[{ }^{2} \mathrm{H}_{4}\right]-1$ and $\left[{ }^{2} \mathrm{H}_{4}\right]-2$. The presence of $\left[{ }^{2} \mathrm{H}_{4}\right]-1$ and $\left[{ }^{2} \mathrm{H}_{4}\right]-2$ was observed again when $\left[{ }^{2} \mathrm{H}_{5}\right]-8$-hydroxygeranial, $\left[{ }^{2} \mathrm{H}_{5}\right]-8$-hydroxyneral, $\left[{ }^{2} \mathrm{H}_{4}\right]-8$ oxogeraniol, $\left[{ }^{2} \mathrm{H}_{4}\right]-8$ oxonerol, $\left[{ }^{2} \mathrm{H}_{4}\right]-8$ oxogeranial and $\left[{ }^{2} \mathrm{H}_{4}\right]-8-$ oxoneral were applied. By contrast, no deuterium labelling was

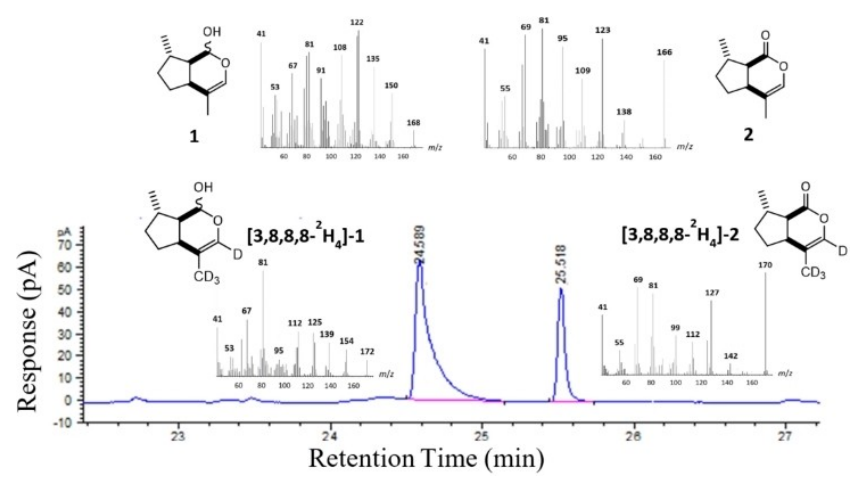

Figure 2. Typical coupled gas chromatography from feeding $\left[{ }^{2} \mathrm{H}_{5}\right]-8$-hydroxygeraniol $20 \mathrm{a}$ - mass spectrometry (GC-MS, $70 \mathrm{eV} \mathrm{EI}+$ ) analysis of pheromone collections from female pea aphids, Acyrthosiphon pisum, following application of synthesized deuterium-labelled compounds listed in Table 1. Insert: mass spectra of unlabelled and deuterium-labelled pheromone components, correlating to unsuccessful and successful deuterium incorporation respectively i) unlabelled nepetalactol 1 ii) unlabelled nepetalactone 2 iii) labelled nepetalactol $\left[3,8,8,8-{ }^{2} \mathrm{H}_{4}\right]-1$ and iv) labelled nepetalactone $\left[3,8,8,8-{ }^{2} \mathrm{H}_{4}\right]-2 .\left[3,8,8,8-{ }^{2} \mathrm{H}_{4}\right]-1$ shows a molecular ion $\mathrm{m} / \mathrm{z} 172$ and a fragment ion $m / z 154$ following loss of $\mathrm{H}_{2} \mathrm{O}$ whilst $\left[3,8,8,8-{ }^{2} \mathrm{H}_{4}\right]-2$ shows a molecular ion $\mathrm{m} / \mathrm{z} 170$ and a fragment ion $\mathrm{m} / \mathrm{z} 142$ following loss of CO.

observed for the pheromone components when any of the labelled forms of $(S)$-citronellol were applied. In the cases where deuterium incorporation was observed, a high level of deuterium incorporation was observed $(>87 \%)$, determined by comparison of the isotopomer peak area. 


\begin{tabular}{|c|c|c|}
\hline $\begin{array}{l}\text { Deuterium-labelled compound applied to female } A \text {. pisum } \\
{\left[8,8,8,10,10,10-{ }^{2} \mathrm{H}_{6}\right] \text {-labelled compounds }}\end{array}$ & $\begin{array}{l}\text { Evidence of deuterium incorporation } \\
\text { in nepetalactol } 1\end{array}$ & $\begin{array}{l}\text { Evidence of deuterium incorporation } \\
\text { in nepetalactone } 2\end{array}$ \\
\hline $\begin{array}{l}\cdot{ }^{2} \mathrm{H}_{6}-\text { Geraniol (14a) } \\
\cdot{ }^{2} \mathrm{H}_{6}-\text { Nerol }(14 \mathrm{~b}) \\
\cdot{ }^{2} \mathrm{H}_{6}-(\mathrm{S}) \text {-Citronellol }(14 \mathrm{c}) \\
\cdot{ }^{2} \mathrm{H}_{6}-\text { Geranial }(15 \mathrm{a}) \\
\cdot{ }^{2} \mathrm{H}_{6}-\text { Neral }(15 \mathrm{~b}) \\
\cdot{ }^{2} \mathrm{H}_{6}-(\mathrm{S}) \text {-Citronellal (15c) } \\
{\left[8,8,10,10,10-{ }^{2} \mathrm{H}_{5}\right] \text {-labelled compounds }}\end{array}$ & $\begin{array}{l}\times \\
\times \\
\times \\
\times \\
\times \\
\times\end{array}$ & $\begin{array}{l}\times \\
\times \\
\times \\
\times \\
\times \\
\times\end{array}$ \\
\hline $\begin{array}{l}\text { - }{ }^{2} \mathrm{H}_{5}-8 \text {-Hydroxygeraniol (20 a) } \\
\text { - }{ }^{2} \mathrm{H}_{5}-8 \text {-Hydroxynerol (20 b) } \\
\text { - }{ }^{2} \mathrm{H}_{5}-(\mathrm{S})-8 \text {-Hydroxycitronellol }(20 \mathrm{c}) \\
\text { - }{ }^{2} \mathrm{H}_{5}-8 \text {-Hydroxygeranial }(24 \mathrm{a}) \\
\cdot{ }^{2} \mathrm{H}_{5}-8 \text {-Hydroxyneral }(24 \mathrm{~b}) \\
\cdot{ }^{2} \mathrm{H}_{5}-(\mathrm{S})-8 \text {-Hydroxycitronellal }(24 \mathrm{c}) \\
{\left[8,10,10,10-{ }^{2} \mathrm{H}_{4}\right] \text {-labelled compounds }}\end{array}$ & $\begin{array}{l}\sqrt{ } \\
\sqrt{ } \\
\times \\
\sqrt{ } \\
\sqrt{ } \\
\times\end{array}$ & $\begin{array}{l}\sqrt{ } \\
\sqrt{ } \\
\times \\
\sqrt{ } \\
\sqrt{ } \\
\times\end{array}$ \\
\hline $\begin{array}{l}\text { - }{ }^{2} \mathrm{H}_{4}-8 \text {-Oxogeraniol }(17 \mathrm{a}) \\
\text { - }{ }^{2} \mathrm{H}_{4}-8 \text {-Oxonerol }(17 \mathrm{~b}) \\
\text { - }{ }^{2} \mathrm{H}_{4}-8 \text {-(S)-Oxocitronellol }(17 \mathrm{c}) \\
\text { - }{ }^{2} \mathrm{H}_{4}-8 \text {-Oxogeranial }(18 \mathrm{a}) \\
\text { - }{ }^{2} \mathrm{H}_{4}-8 \text {-Oxoneral }(18 \mathrm{~b}) \\
\cdot{ }^{2} \mathrm{H}_{4}-(\mathrm{S})-8 \text {-Oxocitronellal }(18 \mathrm{c})\end{array}$ & $\begin{array}{l}\sqrt{ } \\
\sqrt{ } \\
\times \\
\sqrt{ } \\
\sqrt{ } \\
\times\end{array}$ & $\begin{array}{l}\sqrt{ } \\
\sqrt{ } \\
\times \\
\sqrt{ } \\
\sqrt{ } \\
\times\end{array}$ \\
\hline
\end{tabular}

Biosynthesis of nepetalactones from 8-oxogeranial in plants is thought to be a multi-step process involving reduction and cyclization to generate an activated non-isolable enol intermediate, followed by oxidation to a corresponding lactone. Recently, Lichman et al suggested that these steps are uncoupled and catalysed by different enzymes (ISY, NEPS) with the enol intermediate diffusing between enzyme active sites. ${ }^{[14]}$ Our data suggest that female $A$. pisum aphids are not only able to incorporate 8-oxogeranial as a substrate for nepetalactone production, similar to that observed for plants, but are also able to utilize closely related compounds which only differ in their oxidative state. Incorporation of neryl-derived substrates in nepetalactone biosynthesis as described in our work has not been reported in vivo elsewhere, even in plants although in vitro activity has been observed ${ }^{[8]}$ suggesting that further work on enzyme acceptability of substrates in this biosynthetic pathway needs to be undertaken, as well as confirmation of the stereochemistry of the resulting nepetalactol/nepetalactone. The unacceptability of $\left[{ }^{2} \mathrm{H}_{6}\right]$-alcohols and $\left[{ }^{2} \mathrm{H}_{6}\right]$-aldehydes suggests that $A$. pisum is unable to use non- $\omega$-oxygenated monoterpenoid precursors for sex pheromone biosynthesis. Given the high degree of deuterium incorporation observed for probes that are accepted, unacceptability could be due to either a lack of oxygenase in A. pisum limiting hydroxylation of the $\left[{ }^{2} \mathrm{H}_{6}\right]$-alcohols and $\left[{ }^{2} \mathrm{H}_{6}\right]$-aldehydes, inability of compounds to pass through the haemolymph, or, less likely, aphid dependence on the host plants for availability of the intermediates.

Lichman et al. ${ }^{[14]}$ reported that (S)-8-oxocitronellal is not incorporated as a substrate for NEPS enzymes, and that high concentrations of buffer are required for the formation of the enol intermediate which either undergoes cyclization spontaneously or acts as a substrate for NEPS3, a multi-functional cyclase-dehydrogenase. In our experiments, none of the citronellyl-based labelled compounds (including the 8-oxo variants) resulted in production of labelled nepetalactones, despite the fact that they were performed in vivo, with potential for the presence of all biosynthetic enzymes utilized by the insect. This implies that either (i) unlike for plants, nepetalactone biosynthesis in $A$. pisum occurs via tandem reduction/ cyclization of 8-oxogeranial, as postulated in Figure S2 or (ii) if nepetalactone biosynthesis occurs via a non-concerted process, as for plants, then exogenously added 8-oxocitronellal cannot insert into the pathway, possibly due to the absence of spontaneous enol formation. Interestingly, Lichman et al. showed that cyclization of (S)-8-oxocitronellal i.e. via the enol in high buffer conditions leads to formation of nepetalactols with relative stereochemistry similar to 3 and $\mathbf{4}$, which comprises the sex pheromone for $P$. humuli. It could be that $P$. humuli possesses the enzymology for incorporating citronellyl-derived compounds in pheromone biosynthesis whereas $A$. pisum does not.

Assuming that scenario (ii) above is correct, as A. pisum does not produce nepetalactol $\mathbf{3}$, one could reasonably expect that citronellyl derivatives will not be accepted. Our early work on sex pheromone identification in aphids detected the presence of $(S)$-citronellol in pheromone collections, with the implication being that it was involved in the biosynthesis of 1 and $2{ }^{[16]}$ However, its presence in collections alongside $\mathbf{1}$ and $\mathbf{2}$ could also be explained by a lack of enzyme acceptability/ suitable enzyme to catalyse cyclization. Further work is required to confirm if $P$. humuli, which utilises $\mathbf{3}$ and $\mathbf{4}$ as a sex pheromone, can incorporate any of the citronellyl derivatives used in this study in sex pheromone production, and to confirm the enzymology involved in aphid sex pheromone biosynthesis.

In summary, we provide evidence for the biosynthesis of $(1 R, 4 \mathrm{a} S, 7 \mathrm{~S}, 7 \mathrm{a} R)$-nepetalactol 1 and $(4 \mathrm{a} S, 7 \mathrm{~S}, 7 \mathrm{a} R)$-nepetalactone 2 
in the pea aphid $A$. pisum. The results suggest that biosynthesis of iridoids in aphids may follow a broadly similar route to that characterized for plants.

\section{Acknowledgements}

This work was supported by a BBSRC Rothamsted-University of Nottingham Doctoral Training Programme (DTP) studentship, which supported Suzanne Partridge during her PhD. The work at Rothamsted Research forms part of the Smart Crop Protection (SCP) strategic programme (BBS/OS/CP/000001) funded through Biotechnology and Biological Sciences Research Council's Industrial Strategy Challenge Fund.

\section{Conflict of Interest}

The authors declare no conflict of interest.

Keywords: biosynthesis - mass spectrometry - molecular probe $\cdot$ pea aphid $\cdot$ sex pheromone

[1] C. A. Dedryver, A. Le Ralec, F. Fabre, C. R. Biol. 2010, 333, 539.

[2] J. A. Pickett, G. I. Aradottir, M. A. Birkett, T. J. A. Bruce, K. Chamberlain, Z. R. Khan, C. A. O. Midega, L. E. Smart, C. M. Woodcock, Physiol. Entomol. 2012, 37, 2.
[3] J. A. Pickett, R. K. Allemann, M. A. Birkett, Nat. Prod. Rep. 2013, 30, 1277.

[4] R. T. Glinwood, W. Powell, C. P. M. Tripathi, Biocon. Sci. Technol. 1998, 8, 607.

[5] J. Hardie, J. R. Storer, F. J. Cook, C. A. M. Campbell, L. J. Wadhams, R. Lilley, L. Peace, Physiol. Entomol. 1996, 21, 97.

[6] W. Powell, J. A. Pickett, Pest Manage. Sci. 2003, 59, 149.

[7] F. Geu-Flores, N. H. Sherden, V. Courdavault, V. Burlat, W. S. Glenn, C. Wu, E. Nims, Y. Cui, S. E. O'Connor, Nature. 2012, 492, 138.

[8] F. Alagna, F. Geu-Flores, H. Kries, F. Panara, L. Baldoni, S. E. O'Connor, A. Osbourn, J. Biol. Chem. 2016, 291, 5542.

[9] H. Kries, F. Kellner, M. O. Kamileen, S. E. O'Connor, J. Biol. Chem. 2017, 292, 14659.

[10] N. H. Sherden, B. Lichman, L. Caputi, D. Zhao, M. O. Kamileen, C. R. Buell, S. E. O'Connor ${ }_{L}$ Phytochemistry. 2018, 145, 48.

[11] H. Kries, L. Caputi, C. E. M. Stevenson, M. O. Kamileen, N. H. Sherden, F. Geu-Flores, D. M. Lawson, S. E. O'Connor, Nat. Chem. Biol. 2016, 12, 6.

[12] Y. Hu, W. Liu, S. R. Malwal, Y. Zheng, X. Feng, T. P. Ko, C. C. Chen, Z. Xu M. Liu, X. Han, J. Gao, E. Oldfield, R. T. Guo, Angew. Chem. Int. Ed. Engl. 2015, 54, 15478.

[13] L. Qin, Y. Zhu, Z. Ding, X. Zhang, S. Ye, R. Zhang, J. Struct. Biol. 2016, 194, 224.

[14] B. R. Lichman, M. O. Kamileen, G. R. Titchiner, G. Saalbach, C. E. M. Stevenson, D. M. Lawson, S. E. O'Connor, Nat. Chem. Biol. 2019, 15, 71

[15] F. Luan, A. Mosandl, A. Münch, M. Wüst, Phytochemistry 2005, 66, 295.

[16] G. W. Dawson, J. A. Pickett, D. W. M. Smiley, Bioorg. Med. Chem. 1996, 4, 351.

[17] J. Balsevich, Can. J. Chem. 1983, 61, 1053.

[18] B. Mauchamp, J. A. Pickett, Agronomie 1987, 7, 523.

Manuscript received: March 18, 2020

Version of record online: 


\section{COMMUNICATION}

Natural product biosynthesis in animals: Chemical synthesis of isotopically-labelled molecular probes and topical application using female pea aphids, Acyrthosiphon pisum, are deployed along with coupled GCmass spectrometry (GC-MS) to show

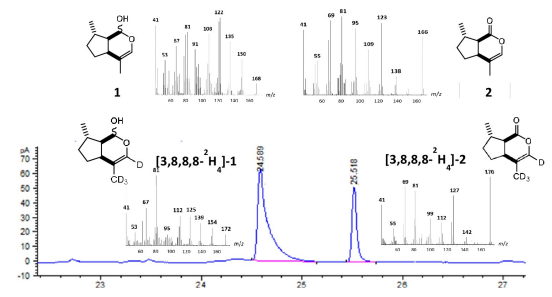
that biosynthesis of the femaleproduced aphid sex pheromone components $(1 R, 4 \mathrm{a} S, 7 \mathrm{~S}, 7 \mathrm{a} R)$-nepetalactol (1) and (4aS,7S,7aR)-nepetalactone (2) may follow a broadly similar route to that characterized for plants.
Dr. S. J. Partridge, Dr. D. M. Withall, Dr. J. C. Caulfield, Prof. J. A. Pickett, Prof. R. A. Stockman, Prof. N. J. Oldham, Dr. M. A. Birkett*

$1-5$

Iridoid Sex Pheromone Biosynthesis in Aphids Mimics Iridoid-Producing Plants 